\title{
Alterações hemostáticas em pacientes com doença falciforme
}

\section{Changes in hemostasis in sickle cell disease patients}

Jaine B. Stypulkowski ${ }^{l}$

Vanusa Manfredini ${ }^{2}$

\begin{abstract}
A doença falciforme (DF) é uma doença hereditária que tem uma fisiopatologia complexa e diversificada. Além da falcização dos eritrócitos, responsável pelos fenômenos de vaso-oclusão e hemólise, alterações no sistema de coagulação parecem ter papel importante nas várias manifestações clínicas desta doença. Aproximadamente todos os componentes da hemostasia, incluindo função plaquetária, mecanismos procoagulantes, anticoagulantes e sistema fibrinolítico, estão alterados nesta patologia, mesmo em pacientes clinicamente estáveis. A presença da fosfatidilserina (FS) na superficie externa da membrana do eritrócito e o aumento dos anticorpos antifosfolipídeos e do fator tecidual (FT) marcam o início da ativação da coagulação nestes pacientes. Também a destruição dos eritrócitos diminui a biodisponibilidade do óxido nítrico (NO) e, como consequência, modifica a hemostasia vascular, aumentando a ativação plaquetária e a adesão de moléculas ao endotélio. Assim, o objetivo deste trabalho foi abordar as diferentes alterações hemostáticas que ocorrem nos pacientes com doença falciforme, a fim de melhor compreender o estado "hipercoagulável" como é descrito nesta doença. Rev. Bras. Hematol. Hemoter.
\end{abstract}

Palavras-chave: Coagulação sanguínea; anemia; anemia falciforme.

\section{Introdução}

Doença falciforme (DF) é um grupo de alterações hereditárias caracterizadas pela presença da hemoglobina $\mathrm{S}(\mathrm{HbS})$, resultante da substituição do ácido glutâmico pela valina na posição seis da cadeia $b$ da globina. ${ }^{1}$ É, em geral, a hemoglobinopatia que apresenta maior gravidade clínica e hematológica. ${ }^{1-4}$ Essa modificação, portanto, resulta na síntese da $\mathrm{HbS}$, uma variável estrutural, ao invés da hemoglobina normal denominada $\mathrm{HbA}$. A presença da $\mathrm{HbS}$ altera as propriedades físico-químicas dos eritrócitos. No estado oxigenado, a molécula de HbS está "relaxada", e nesta conformação estrutural as globinas beta $\mathrm{S}$ estão mais separadas. No estado desoxigenado (desoxi-Hb), a molécula de $\mathrm{HbS}$ torna-se tensa e as globinas beta $\mathrm{S}$ ficam mais próximas. Essa mudança de conformação favorece o contato entre as regiões da desoxi-
$\mathrm{Hb}$, o que não é possível no estado oxigenado. Por meio da união de vários tetrâmeros de $\mathrm{HbS}$, forma-se um número considerável de moléculas agregadas, que geram longos polímeros, os quais se precipitam no citoplasma, alterando a morfologia do eritrócito para o formato de foice., ${ }^{5,6}$ Nesta etapa há mudança do estado líquido e solúvel para o estado sólido e insolúvel, alterando-se a viscosidade da solução e formando-se cristais de $\mathrm{HbS}$. Essa alteração da solubilidade é a diferença estrutural mais marcante do ponto de vista patológico da presença da $\mathrm{HbS}$. A polimerização da $\mathrm{HbS}$ é dependente de vários fatores, como: tensão de oxigênio, concentração intracelular da $\mathrm{HbS}$, temperatura e associação com outras hemoglobinas e talassemias. ${ }^{4,5,6}$ A polimerização da $\mathrm{HbS}$ aumenta a viscosidade e promove eventos vaso-oclusivos e hemolíticos nos pacientes com DF, os quais podem desencadear complicações trombóticas futuras. ${ }^{7-10}$

\footnotetext{
${ }^{I}$ Farmacêutica bioquímica do Hospital Cidade de Passo Fundo, RS

${ }^{2}$ Farmacêutica bioquímica. Professora do Curso de Especialização em Hematologia e Hemoterapia da Universidade de Passo Fundo, RS e do Curso de Farmácia da Universidade Regional Integrada do Alto Uruguai e das Missões - URI, Campus de Erechim, RS
}

Universidade de Passo Fundo, RS.

Correspondência: Vanusa Manfredini Av. Sete de Setembro, 1621 - Prédio 12 99700-000 - Erechim, RS - Brasil

Tel.: (55 54) 3520-9000 ramal 9073

E-mail:vanusa_manfredini@yahoo.com.br 
A membrana dos eritrócitos com HbS está constantemente exposta a danos mecânicos que provocam hemólise, caracterizando uma anemia hemolítica intravascular crônica. Esse processo hemolítico causa a liberação da hemoglobina livre e da enzima arginase no plasma, produzindo um estado de disfunção endotelial, proliferação vascular, estresse oxidativo e inflamação. ${ }^{10,11}$ A fisiopatologia da DF é complexa e caracterizada por episódios de oclusão vascular, polimerização da $\mathrm{HbS}$ e obstrução mecânica induzida por eritrócitos irreversivelmente falciformes, os quais incluem aderência de elementos sanguíneos nas células endoteliais, coagulopatias e disfunção endotelial. ${ }^{11,12,13}$

Quase todos os componentes da hemostasia, incluindo função plaquetária, mecanismos procoagulantes, anticoagulantes e sistema fibrinolítico, estão alterados na DF. Em numerosos estudos, os pacientes têm mostrado elevados níveis de trombina, aumento na ativação da fibrinólise, diminuição dos níveis de proteínas anticoagulantes, ativação de plaquetas, fator tecidual (FT) e de outros elementos celulares. Essas constatações levaram à ideia de que a DF é caracterizada por um estado de "hipercoagulabilidade", mesmo em pacientes clinicamente estáveis. Pacientes com diversas síndromes talassêmicas também mostraram semelhante ativação da coagulação. ${ }^{12,14,15}$

Outro fator que pode contribuir para o estado de "hipercoagulabilidade" nos pacientes com essa doença genética é a interação que ocorre entre os eritrócitos irreversivelmente falcizados e o endotélio vascular ou subendotélio. Essas disfunções no sistema hemostático frequentemente provocam complicações trombóticas, incluindo embolia pulmonar, trombose pulmonar e infarto. ${ }^{15} \mathrm{As}$ principais mudanças nos componentes do sistema hemostático que levam a essas complicações são discutidas neste artigo a fim de melhor se compreenderem os mecanismos desta coagulopatia.

\section{Alterações eritrocitárias e ativação endotelial}

A polimerização da $\mathrm{HbS}$ deforma o eritrócito, levando a célula a perder seu formato discoide, tornando-se alongada e com filamentos na sua extremidade. . $^{1,2,4} \mathrm{~A}$ sequência que causa a deformação dos eritrócitos discoides em falcizados altera a funcionalidade da bomba $\mathrm{Na}^{+} / \mathrm{K}^{+}$, com consequente perda de potássio e água, tornando os eritrócitos mais densos e favorecendo o aumento de polímeros de HbS. Ocorre também a elevação da concentração intracelular de cálcio, pela falência da bomba de $\mathrm{Ca}^{2+} /$ ATPase e, consequentemente, aumento da concentração de hemoglobina corpuscular média $(\mathrm{CHCM})$ da desoxi-HbS. Todas essas alterações diminuem a capacidade da permeabilidade celular. ${ }^{7,16,17}$ A contínua alteração da morfologia dos eritrócitos com $\mathrm{HbS}$ provoca lesões crônicas da membrana celular, a ponto de o eritrócito tornar-se irreversivelmente falcizado, acentuando os problemas não só em nível celular como também em nível circulató- rio. Dentre as alterações da membrana têm-se os seguintes eventos: rearranjo das proteínas espectrina-actina, diminuição de glicoproteínas, geração de radicais livres, externalização da fosfatidilserina (FS) e aceleração da apoptose, em virtude do aumento da atividade citosólica de cálcio $\left(\mathrm{Ca}^{2+}\right) \cdot{ }^{16,17}$

$\mathrm{O}$ evento da oclusão microvascular na DF tem uma etiologia multifatorial, dependendo, primeiramente, da concentração de polímeros de $\mathrm{HbS}$ formados. Esses eventos tornam mais lentos o trânsito dos eritrócitos em formato de foice na microcirculação, assim como aumentam a adesão endotelial dos mesmos. ${ }^{15,16} \mathrm{~A}$ vaso-oclusão parece ter início pela adesão das células falciformes no endotélio vascular, seguida do acúmulo secundário de células menos deformadas, levando, assim, à oclusão vascular. ${ }^{16,18}$

Portanto, em nível circulatório, a alteração da plasticidade normal dos eritrócitos desencadeada pelos efeitos polimerizantes da $\mathrm{HbS}$ torna os eritrócitos falcêmicos com maior possibilidade de aderirem ao endotélio vascular. As proteínas plasmáticas, como o fator de Von Willebrand, trombospondina, fibrinogênio e fibronectina, também participam da ligação dos eritrócitos falcêmicos às células endoteliais. Como consequência da elevada adesividade do eritrócito falcêmico ao endotélio vascular ocorre a estase venosa, que desencadeia a hipóxia tecidual, levando mais moléculas de $\mathrm{HbS}$ ao estado de desoxi-HbS, exacerbando uma situação circulatória já desfavorável e, assim, lesando os tecidos perfundidos por esses capilares. Os tecidos mal perfundidos sofrem infartos, com necrose e formação de fibrose, principalmente no baço, medula óssea e placenta. ${ }^{18}$ Todos esses eventos provocam lesões teciduais agudas, com crises de dores e lesões crônicas e progressivas de órgãos. ${ }^{19,20}$

Células endoteliais de pacientes com DF mostram aumento da expressão de ICAM 1 (molécula de adesão intracelular 1), VCAM -1 (molécula de adesão vascular 1), Eselectina, P-selectina e FT. ${ }^{21,22,23}$ A expressão dessas moléculas de adesão ao endotélio vascular está aumentada mesmo em pacientes com DF clinicamente estáveis, porém sua manifestação se acentua durante as crises dolorosas. Essa ativação crônica do endotélio parece ser responsável pela vasculopatia dos grandes e pequenos vasos..$^{18,23,24}$ Essas alterações na hemostasia também já foram relatadas em indivíduos heterozigotos para a anemia falciforme. ${ }^{25}$

O FT é um importante iniciador da coagulação e sua expressão está significativamente aumentada em pacientes com DF, a qual aumenta com episódios de dor aguda. ${ }^{24} \mathrm{O}$ FT está presente na superfície celular como uma proteína integral de membrana. Em condições fisiológicas, o FT geralmente não é expresso em células de contato direto com o sangue, tais como células endoteliais e leucócitos. ${ }^{26}$ Numerosos componentes plasmáticos podem aumentar a expressão do FT em células hematopoéticas e/ou em células endoteliais, como trombina, interleucina-1 (IL-1), fator de necrose tumoral alfa (TNF- $\alpha$ ), endotoxina e proteína $C$ reativa (PCR). Estudos recentes mostram que esses fatores se encontram elevados 
nos pacientes com DF. De fato, as células endoteliais circulantes expressam muito FT em pacientes com DF. ${ }^{13,23} \mathrm{~A}$ interação do FT com o fator VIIa resulta na ativação de serinoproteases, incluindo fatores IX, X, XII e trombina, desencadeando a cascata de coagulação..$^{24,27,28}$

\section{Fosfolipídeos}

A distribuição de fosfolipídeos na membrana celular de eritrócitos é assimétrica; assim, os aminofosfolipídeos, FS e fosfatidiletanolamina localizam-se quase exclusivamente na superfície interna da membrana. Esta disposição é mantida pelo sistema específico de translocação de fosfolipídeos, como o movimento "flip-flop" realizado pela flipase. ${ }^{29,30} \mathrm{Con}$ tudo, a membrana dos eritrócitos falciformes mostra significativa alteração na assimetria dos fosfolipídeos, que pode ser observada tanto nos reticulócitos como nos eritrócitos maduros já na corrente circulatória, ocorrendo exteriorização da FS. A exposição anormal deste fosfolipídio ocorre como consequência de repetidos ciclos de falcização e desfalcização do eritrócito falciforme. ${ }^{21,30}$

A presença da FS na superfície externa da membrana do eritrócito parece estar relacionada com a progressão da DF. A externalização da FS é responsável pela ativação de proteínas da coagulação, ativação plaquetária, aumento da expressão de moléculas de adesão do endotélio vascular e da anemia, tendo em vista que estas células, diferentes dos eritrócitos normais, são reconhecidas e removidas pelo sistema fagocitário, diminuindo assim sua meia vida na corrente circulatória. $^{22,31}$

O estado "hipercoagulável" da DF parece estar diretamente relacionado com essas anormalidades da membrana do eritrócito. Tem sido demonstrado que os eritrócitos em formato de foice ativam as plaquetas e aumentam a conversão de protrombina em trombina, e micropartículas produzidas por fragmentos de eritrócitos durante a hemólise ativam a via extrínseca da coagulação sanguínea e a geração de trombina. ${ }^{10,12} \mathrm{O}$ fragmento $1+2$ da protrombina $(\mathrm{F} 1+2)$, que marca a geração de trombina, está associado com eritrócitos FS - positivos, sugerindo que a exposição desse fosfolipídio de membrana produz in vivo ativação da coagulação na $\mathrm{DF}$. Finalmente, a hemoglobina fetal ( $\mathrm{HbF})$ pode ter aqui um papel protetor, pois os eritrócitos que a expressam em maior concentração apresentam menor exposição da FS e, assim, geram menor quantidade de trombina. ${ }^{13,14,22}$

Os anticorpos antifosfolipídeos são conhecidos por terem efeitos procoagulantes e protrombóticos. Níveis de anticorpos antifosfolipídeos, principalmente os dirigidos a FS, estão pronunciadamente elevados em pacientes homozigotos (HbSS). Nestes existe uma forte correlação entre anticorpos antifosfolipídeos contra FS e D-dímeros plasmáticos, sugerindo uma importante função desses anticorpos na ativação da coagulação na DF, o que pode também ser consequência da indução do FT por anticorpos contra FS. ${ }^{32,33}$
Recente estudo aponta que a condição inflamatória da DF pode também contribuir para o estado "hipercoagulável" nesses pacientes. ${ }^{25}$

\section{Trombina}

A trombina exibe atividade procoagulante, convertendo o fibrinogênio em fibrina, facilitando a ativação plaquetária e do fator XIII da coagulação, que, por sua vez, estabiliza o coágulo de fibrina entre outros. ${ }^{31}$

A avaliação indireta dos níveis plasmáticos de trombina sugere que pacientes com DF tenham seus níveis aumentados. Registram-se também aumentos dos níveis do F1+2, de D-dímeros e de complexos trombina-antitrombina. ${ }^{14,21}$

Uma vez iniciada a cascata de coagulação pelo FT, o fator Xa forma um complexo protrombinase com o fator Va e participa da clivagem de protrombina em trombina e $\mathrm{F} 1+2{ }^{8,12,24}$

$\mathrm{O}$ aumento na concentração plasmática do $\mathrm{F} 1+2^{32} \mathrm{e} \mathrm{a}$ redução nos níveis plasmáticos de fator $\mathrm{V}$ nos pacientes com DF sugerem aumento na geração de trombina. ${ }^{33,34,35} \mathrm{~A}$ trombina degrada o fibrinogênio formando fibrinopeptídeo A e fibrinopeptídeo $\mathrm{B}$ e dando origem, assim, à fibrina solúvel. ${ }^{8}$ Aumento nos níveis de fibrinopeptídeo A também foi observado em pacientes com DF, com consequente aumento na proteólise do fibrinogênio. A degradação do coágulo de fibrina pela plasmina forma os D-dímeros, que são produtos muito utilizados como marcador sorológico da coagulação. ${ }^{8}$ Estudos propõem que marcadores plasmáticos de fibrinólise, Ddímeros e o complexo plasmina-antiplasmina parecem estar significativamente aumentados em pacientes com DF clinicamente estáveis, quando comparados com indivíduos normais. $^{28,31,32,36}$

A frequência de episódios dolorosos agudos em pacientes com DF está correlacionada com a extensão da atividade fibrinolítica (avaliado pelos níveis de D-dímeros plasmáticos); assim, os níveis de D-dímeros podem predizer a frequência de crises dolorosas. ${ }^{32}$

\section{Anticoagulantes naturais}

Em condições normais, as reações bioquímicas da coagulação sanguínea são reguladas por proteínas inibitórias que atuam como anticoagulantes naturais, entre elas, a proteína C (PrC), a proteína $\mathrm{S}$ (PrS) e a antitrombina (AT). ${ }^{15}$ Pacientes com DF clinicamente estáveis apresentam baixos níveis de $\mathrm{PrC}$ e $\mathrm{PrS}$ circulantes, as quais diminuem ainda mais nos episódios de crises dolorosas. ${ }^{15,21}$ Baixos níveis dessas proteínas regulatórias podem ser consequência do seu consumo crônico, em razão do aumento da geração de trombina resultante da elevação da expressão do FT intravascular e da atividade protrombinase eritrocitária. Também ocorre um aumento da ligação de PrS nos eritrócitos falciformes em virtude da exposição da FS na membrana, e/ou da inibição da 
ligação de PrS com b2-glicoproteína 1 pelos anticorpos antifosfolipídeos, resultando na inativação da PrS pela proteína transportadora da fração $\mathrm{C} 4$ do complemento. ${ }^{13,17}$ Os níveis de $\mathrm{PrC}$ e PrS em crianças com DF que tiveram infartos trombóticos encontravam-se significativamente diminuídos quando comparados com os de crianças com DF que não haviam sofrido tais eventos. ${ }^{15,21,33}$

Embora existam algumas discordâncias sobre o nível da AT no paciente com DF clinicamente estável e durante as crises vaso-oclusivas, um estudo ${ }^{37}$ relatou uma diminuição significativa nos níveis de AT em pacientes com DF e b-talassemia que apresentam úlceras crônicas, nos quais a infusão de um concentrado de AT diminuiu a geração de trombina, possibilitando a cicatrização das ulcerações. ${ }^{13,15,23}$

\section{Plaquetas}

Existem muitas evidências de que as plaquetas circulantes em pacientes com DF estão cronicamente ativadas, podendo, assim, contribuir para o estado "hipercoagulável" observado nesta patologia. ${ }^{12,13,15}$ A trombocitose está relacionada com a asplenia funcional, comum nos pacientes falcêmicos após os primeiros anos de vida. ${ }^{13,21}$ A alteração qualitativa traduz-se por um estado de ativação plaquetária que parece estar relacionada com um número elevado de megacariócitos circulantes e um aumento da concentração de alguns agonistas plaquetários, como a adrenalina, trombina e adenosina difosfato (ADP). ${ }^{11,27}$

Em pacientes com DF, os marcadores da ativação plaquetária P-selectina, CD40-L, fator plaquetário 4 (FP4) e b-tromboglobulina estão aumentados quando comparados com indivíduos normais. ${ }^{28,34,35}$ Também os doentes falciformes têm diminuição do conteúdo de trombospondina-1 plaquetária, que, provavelmente, está relacionada com a ativação plaquetária precoce. ${ }^{38}$

A diminuição na sobrevida plaquetária e trombocitopenia têm sido relatadas durante episódios de crises dolorosas agudas. Essa diminuição é seguida de um aumento na contagem de plaquetas e megacariócitos, atingindo o pico em 10 a 14 dias após o período da crise. Esses achados sugerem que a diminuição da sobrevida plaquetária e o aumento do consumo ocorrem durante episódios agudos de dor, sendo provavelmente resultado da deposição plaquetária nas paredes do endotélio vascular. ${ }^{23,38}$

\section{Óxido nítrico}

Um aspecto importante na vasculopatia da DF é a deficiência na regulação endotelial do tônus vascular, trombose e inflamação. A redução da biodisponibilidade do óxido nítrico (NO) na DF é um componente crítico nessa anormalidade. ${ }^{39,40}$

Estudos apontaram que mais de $50 \%$ dos pacientes com DF apresenta disfunção endotelial em razão da baixa biodisponibilidade endógena do NO. Pesquisas recentes apontam novos alvos de investigações terapêuticas direcionadas a reestabelecer a biodisponibilidade desse gás. ${ }^{40}$

O NO é um gás solúvel com meia vida de segundos, ${ }^{41}$ continuamente produzido por uma família de enzimas chamadas óxido nítrico sintetases (NOS), localizadas numa variedade de tipos celulares, desde o endotélio vascular até os neurônios. ${ }^{40,42}$ As enzimas NOS catalisam a formação de L-citrulina e NO a partir da L-arginina. Os efeitos biológicos do NO são iniciados pela ativação da enzima heterodimérica guanil ciclase solúvel (GCs) e por outras reações químicas. ${ }^{42}$

O NO é um potente regulador do tônus da musculatura lisa vascular, promovendo vasodilatação pelo relaxamento da musculatura lisa do vaso. ${ }^{43}$ Além disso, o NO é uma molécula polivalente que exerce um papel importante na regulação da hemostasia, sendo responsável pela inibição da expressão endotelial de moléculas de adesão e inibição plaquetária em todos os seus níveis de atuação, desde adesão até agregação, impedindo, dessa forma, posterior formação de trombo. ${ }^{42}$ Também promove o fluxo sanguíneo por inibição da expressão de células de moléculas de adesão e células endoteliais e inibição de proteínas procoagulantes. ${ }^{42,43}$

$\mathrm{O}$ NO produzido pelas células endoteliais difunde-se na corrente sanguínea e é inativado pela oxi-hemoglobina (oxi-Hb) eritrocitária, com formação da meta-hemoglobina (met-Hb) e íons nitrato. ${ }^{42}$ Também contribuem para a limitada difusão do NO a membrana e as proteínas do citoesqueleto dos eritrócitos..$^{44} \mathrm{O} \mathrm{NO}$ pode ainda reagir com o grupo heme da desoxi-Hb, formando compostos que se comportam como fontes bioativas de $\mathrm{NO} .{ }^{45}$ Assim, a hemoglobina pode atuar quer como inativadora de $\mathrm{NO}$, quer como transportadora deste gás na circulação. ${ }^{42}$

O fluxo sanguíneo laminar e a compartimentalização da hemoglobina dentro dos glóbulos vermelhos constituem barreiras naturais para o consumo de NO pela hemoglobina. ${ }^{46}$ Por outro lado, a hemoglobina livre no plasma resultante de hemólise intravascular converte NO em nitrato inativo, limitando a biodisponibilidade do $\mathrm{NO}$ em pacientes com DF. ${ }^{39}$ Esta diminuição de NO é justificada pelo aumento dos níveis plasmáticos de oxi-Hb, em razão da hemólise intravascular. A oxi-Hb tem a capacidade de bloquear as respostas ao NO endógeno e exógeno, promovendo a diminuição da atividade da GCs, o que conduz à redução da vasodilatação e da antiagregação plaquetária, com consequente disfunção de vários órgãos. ${ }^{42}$ Desse modo, a hemólise intravascular produz um estado de resistência para vasodilatação dependente de NO. Durante as crises dolorosas vaso-oclusivas e síndrome toráxica aguda (STA), a hemólise intensifica-se com o aumento da hemoglobina plasmática, sugerindo que o consumo, ou inativação, de NO pode provocar uma maior instabilidade vascular durante as crises. . $^{39,41,44}$

A L-arginina, o precursor do NO, pode ter seus níveis reduzidos quando ocorre hemólise em virtude da liberação da arginase eritrocitária, a qual converte a L-arginina em 
ornitina. ${ }^{47,48}$ Outro possível mecanismo para a redução de NO é a diminuição da síntese de L-arginina em nível renal, pois a insuficiência renal é frequente nos doentes com DF. O papel patológico das alterações do metabolismo da L-arginina é constatado pela relação inversa entre a razão [arginina]/ [ornitina], podendo estar relacionado com a progressão da hipertensão pulmonar e com o aumento da morbi-mortalidade nestes doentes. ${ }^{48,49,50}$

A xantina oxidase (XO) está elevada em pacientes com DF. Durante os ciclos de hipóxia, a XO é liberada pelo fígado para a corrente circulatória e catalisa a produção de ânion superóxido $\left(\mathrm{O}_{2}{ }^{-}\right)$e peróxido de hidrogênio $\left(\mathrm{H}_{2} \mathrm{O}_{2}\right)$. Estas espécies reativas de oxigênio (ERO), ao interagirem com o $\mathrm{NO}$, contribuem para a sua diminuição. ${ }^{42}$

A importância desses mecanismos de alteração do metabolismo do NO parece ser relevante nas crises vasooclusivas agudas da DF. Estudos recentes mostram uma redução significativa dos níveis de NO em pacientes com DF que apresentam episódios de dor álgida. Também propõem que a medida indireta deste gás pode ser considerada como um marcador da gravidade da crise de dor. ${ }^{21,39}$ Pesquisa desenvolvida por Kato e colaboradores ${ }^{51}$ sugere a inalação diária do NO ou a suplementação da L-arginina em pacientes com DF a fim de diminuir as crises vaso-oclusivas. ${ }^{49,51,52-55}$

A baixa biodisponibilidade do NO altera a hemostasia vascular, aumentando a ativação plaquetária e a expressão endotelial de moléculas de adesão, provocando vasoconstrição, o que aumenta a possibilidade de vaso-oclusão. ${ }^{44,51,56}$ $\mathrm{Na} \mathrm{DF}$, o aumento do NO parece ter papel preponderante na propensão ao desenvolvimento de acidente vascular cerebral (AVC), hipertensão pulmonar, úlceras de membros inferiores e priaprismo..$^{7,57}$

\section{Implicações terapêuticas}

Apesar de inúmeras evidências laboratoriais da hipercoagulabilidade observada nos pacientes com DF, estudos clínicos utilizando agentes anticoagulantes e antiplaquetários não têm mostrado nenhum benefício convincente na prevenção ou tratamento de complicações vaso-oclusivas. Até o presente momento, as investigações clínicas com esses agentes têm sido limitadas.

A inalação de NO nas crianças com DF em crise vasooclusiva aguda melhora substancialmente as queixas de dor e associa-se a uma diminuição do uso de analgésicos opioides. $^{51}$

Os níveis de L-arginina estão diminuídos em pacientes com DF durante os episódios de STA. ${ }^{54,55}$ Estudos propõem a administração oral da L-arginina em doentes com DF, uma vez que diminui significativamente a pressão sistólica na artéria pulmonar. ${ }^{56}$ No entanto, outros estudos clínicos são necessários, de preferência envolvendo um grande número de doentes falciformes, a fim de se poder recomendar a suplementação deste aminoácido.

\section{Considerações finais}

Inúmeras evidências demonstram que ocorre uma ativação hemostática nos pacientes com DF. A ativação da cascata da coagulação neste grupo de doentes parece ser consequência da externalização FS na superfície da membrana do eritrócito, de eventos de isquemia reperfusão e, possivelmente, do aumento do sequestro do NO no endotélio vascular. Não se sabe ao certo se a ativação plaquetária e da cascata da coagulação observada nos doentes falciformes contribuem para a fisiopatologia da DF ou se são eventos secundários a ela. Assim, para elucidar o mecanismo do estado "hipercoagulável", tornam-se necessários mais estudos envolvendo modelos de animais transgênicos e estudos clínicos com agentes antiplaquetários, melhor definindo a contribuição de "hipercoagulabilidade" para a fisiopatologia da DF e suas complicações.

Um maior conhecimento acerca do estado de "hipercoagulabilidade" possibilitará o desenvolvimento de novas abordagens terapêuticas com a finalidade de amenizar os sintomas e prevenir complicações futuras.

\begin{abstract}
Sickle cell disease is an inherited disease characterized by a complex and varied physiopathology. Apart from the sickle red blood cells, responsible for vascular occlusion and hemolytic anemia, changes in the coagulation system seem to play an important role in the clinical manifestations of this disorder. Nearly every component of hemostasis, including platelet function and the procoagulant, anticoagulant, and fibrinolytic systems, are altered in sickle Cell Disease even in non-crisis steady-state patients. The presence of phosphatidylserine on the external membrane of the red blood cell and the increase in antiphosphatidylserine antibodies and tissue factor mark the beginning of coagulation activation in these patients. Moreover, red blood cell destruction decreases the bioavailability of nitric oxide, which modifies hemostasis, increasing platelet activation and the adhesion of molecules to the vascular endothelium. Thus, this study aimed to evaluate several hemostatic changes in patients with sickle cell disease in order to have a better understanding of the "hypercoagulable" state described in this disease. Rev. Bras. Hematol. Hemoter.
\end{abstract}

Key words: Blood coagulation; anemia; sickle cell.

\section{Referências Bibliográficas}

1. Herrick JB. Peculiar elongated and sickle-shaped red blood corpuscles in a case of severe anemia. 1910. Yale J Biol Med. 2001;74(3):179-84

2. Pauling L, Itano HA, et al. Sickle cell anemia, a molecular disease. Science. 1949;110(2865):543-8.

3. Perutz MF, Mitchison JM. State of hemoglobin in sickle-cell anemia. Nature. 1950;166(4225):677-9.

4. Perutz MF. Molecular pathology of human haemoglobin. Biochimie. 1972;54(5):621-3 
5. Eaton WA. Linus Pauling and sickle cell disease. Biophys Chem. 2003;100(1-3):109-16

6. Eaton WA, Hofrichter J. Hemoglobin S gelation and sickle cell disease. Blood. 1987;70(5):1245-66.

7. Frenette PS, Atweh GF. Sickle cell disease: old discoveries, new concepts, and future promise. J Clin Invest. 2007;117(4):850-8.

8. Loggetto SR, Braga JAP, Carvalho BTC, Sale D. Immunological disorders in Sickle Cell Disease. Rev. Bras. Alerg. Imonupatol. 1999;22:77-82.

9. Figueiredo MS. Fatores moduladores da gravidade da evolução clínica da anemia falciforme. Rev. Bras. Hematol. Hemoter. 2007; 29(3):215-7.

10. Ataga KI, Moore CG, Hillery CA, Jones S, Whinna HC, Strayhorn $\mathrm{D}$, et al. Coagulation activation and inflammation in sickle cell disease-associated pulmonary hypertension. Haematologica. 2008; 93(1):20-6

11. Aslan M, Freeman BA. Redox - dependent impairment of vascular function in sickle cell disease. Free Radic Biol Med. 2007;43(11): 1469-83.

12. Gladwin MT, Kato GJ. Hemolysis-associated hypercoagulability in sickle cell disease: the plot (and blood) thickens! Haematologica. 2008;93(1):1-3.

13. Cappellini MD. Coagulation in the pathophysiology of hemolytic anemias. Hematology Am Soc Hematol Educ Program. 2007: 74-8.

14. Setty BNY, Rao AK, Stuart MJ. Thrombophilia in sickle cell disease: the red cell connection. Blood. 200;98(12):3228-33.

15. Lubin BH. Sickle cell disease and the endothelium [editorial]. N. Engl J Med. 1997;337(22):1623-25.

16. Gibson JS, Ellory JC. Membrane transport in sickle cell disease. Blood Cells Mol Dis. 2002;28(3):303-14.

17. Brugnara C. Sickle cell disease: from membrane pathophysiology to novel therapies for prevention of erythrocyte dehydration. J Pediatr Hematol Oncol. 2003;25(12):927-33.

18. Ataga KI, Orringer EP. Hypercoagulability in sickle cell disease: A curious paradox. Am J Med. 2003;115(9):721-8.

19. Villagra J, Shiva S, Hunter LA, Machado RF, Gladwin MT, Kato GJ. Platelet activation in patients with sickle disease, hemolysisassociated pulmonary hypertension, and nitric oxide scavenging by cell-free hemoglobin. Blood. 2007;110(6):2166-72.

20. Steinberg MH. Pathophysiologically based drug treatment of sickle cell disease. Trends Pharmacol Sci. 2006;27(4):204-10.

21. Ataga KI, Key NS. Hypercoagulability in sickle cell disease: New approaches to an old problem. Hematology Am Soc Hemato Educ Program. 2007:91-6.

22. Matsui NM, Varki A, Embury SH. Heparin inhibits the flow adhesion of sickle red blood cells to P-selectin. Blood. 2002;100(10):3790-6

23. Solovey A, Lin Y, Browne P, Choong S, Wayner E, Hebbel RP. Circulating activated endothelial cells in sickle cell anemia. N Engl J Med. 1997;337(22):1584-90.

24. Key NS, Slungaard A, Dandelet L, Nelson SC, Moertel C, Styles LA, et al. Whole blood tissue factor procoagulant activity is elevated in patients with sickle cell disease. Blood. 1998;91(11): 4216-23.

25. Westerman MP, Green D, Gilman-Sachs A, Beaman K, Freels S, Boggio L, et al. Coagulation changes in individual with sickle cell trait. Am J Hematol. 2002;69(2):89-94.

26. Francis RB Jr. Platelets, coagulation, and fibrinolysis in sickle cell disease: their possible role in the vascular occlusion. Blood Coagul Fibrinolysis. 1991;2(2):341-53.

27. Yasin Z, Witting S, Palascak MB, Joiner CH, Rucknagel DL, Franco RS. Phosphatidylserine externalization in sickle red blood cells: associations with cell age, density, and hemoglobin F. Blood. $2003 ; 102(1): 365-70$

28. Kurantsin-Mills J, Ofosu FA, Safa TK, Siegel RS, Lessin LS. Plasma factor VII and thrombin-antithrombin III levels indicate increased tissue factor activity in sickle cell patients. Br J Haematol. 1992; 81(4):539-44

29. Setty BN, Kulkarni S, Stuart MJ. Role of erythrocyte phosphatidylserine in sickle red cell-endothelial adhesion. Blood. 2002;99(5):1564-71.

30. Franck PF, Bevers EM, Lubin BH, Comfurius P, Chiu DT, Op den Kamp JA, et al. Uncoupling of the membrane skeleton from the lipid bilayer. The cause of accelerated phospholipid flip-flop leading to an enhanced procoagulant activity of sickled cells. Clin Invest. 1985;75(1):183-90

31. Monroe DM, Hoffman M, Roberts HR. Platelets and thrombin generation. Arterioscler Thromb Vasc Biol. 2002;22(9):1381-9.

32. Tomer A, Harker LA, Kasey S, Eckman JR. Thrombogenesis in sickle cell disease. J Lab Clin Med. 2001;137(6):398-407

33. Westerman MP, Green D, Gilman-Sachs A, Beaman K, Freels S, Boggio L, et al. Antiphospholipid antibodies, protein $\mathrm{C}$ and $\mathrm{S}$, and coagulation changes in sickle cell disease. J. Lab Clin Med. 1999; 134(4):352-62.

34. Wun T, Paglieroni T, Tablin F, Welborn J, Nelson K, Cheung A. Platelet activation and platelet-erythrocyte aggregates in patients with sickle cell disease. J Lab Clin Med. 1997; 129 (5): 507-16.

35. Lindmark E, Tenno T, Siegbahn A. Role of platelet P-selectin and CD40 ligand in the induction of monocytic tissue factor expression. Arterioscler Thromb Vasc Biol. 2000;20(10):2322-8.

36. Devine DV, Kinney TR, Thomas PF, Rosse WF, Greenberg CS Fragment D-dimer levels: an objective marker of vaso-occlusive crisis and other complications of sickle cell disease. Blood. 1986;68(1):317-9.

37. Cacciola E, Giustolisi R, Musso R, Longo A, Cacciola E. Antithrombin III concentrate for treatment of chronic leg ulcers in sickle cell-beta thalassemia: a pilot study. Ann Intern Med. 1989;111(6):534-6.

38. Browne PV, Mosher DF, Steinberg MH, Hebbel RP. Disturbance of plasma and platelet thrombospondin levels in sickle cell disease. Am J Hematol. 1996;51(4):296-301.

39. Mack AK, Kato GJ. Sickle cell disease and nitric oxide: A paradigm shift? Int J Biochem Cell Biol. 2006;38(8):1237-43.

40. Gladwin MT, Crawford JH, Patel RP. The biochemistry of nitric oxide, nitrite, and hemoglobin: role in blood flow regulation. Free Radic Biol Med. 2004;36(6):707-17.

41. Furchgott RF, Zawadzki JV. The obligatory role of endothelial cells in the relaxation of arterial smooth muscle by acethylcholine. Nature. 1980;288(5789):373-6.

42. Halliwell B, Gutteridge JMC. Free Radicals in Biology and Medicine, 3rd Ed, Oxford University Press, NY, 2007.

43. Vanni DS, Horstmann B, Benjo AM, Daher JPL, Kanaan S, Sleiman M. Nitric oxide: inhibition of platelets and participation in trombus formation. J. Bras. Patol. Med. Lab. 2007;43:181-9.

44. Huang KT, Han TH, Hyduke DR, Vaughn MW, Van Herle H, Hein $\mathrm{TW}$, et al. Modulation of nitric oxide bioavailability by erythrocytes. Proc Natl Acad Sci U S A. 2001;98(20):11771-6.

45. McMahon TJ, Moon RE, Luschinger BP, Carraway MS, Stone AE, Stolp BW, et al. Nitric oxide in the human respiratory cycle. Nat Med. 2002;8(7):711-7.

46. Azarov I, Huang KT, Basu S, Gladwin MT, Hogg N, Kim-Shapiro DB. Nitric oxide scavenging by red blood cells as a function of hematocrit and oxygenation. J Biol Chem. 2005;280(47):39024-32. 
47. Schnog JJ, Jager EH, van der Dijs FP, Duits AJ, Moshage H, Muskiet $\mathrm{FD}$, et al. Evidence for a metabolic shift of arginine metabolism in sickle cell disease. Ann Hematol. 2004;83(6):371-5.

48. Morris CR, Kato GJ, Poljakovic M, Wang X, Blackwelder WC, Sachdev V, et al. Dysregulated arginine metabolism, hemolysisassociated pulmonary hypertension, and mortality in sickle cell disease. JAMA. 2005;294(1):81-90.

49. Lopez BL, Davis-Moon L, Ballas SK, Ma XL. Sequential nitric oxide measurements during the emergency department treatment of acute vasoocclusive sickle cell crisis. Am J Hematol. 2000;64 (1):15-9

50. Rother RP, Bell L, Hillmen P, Gladwin MT. The clinical sequelae of intravascular hemolysis and extracellular plasma hemoglobin. JAMA. 2005;293(13):1653-62.

51. Kato GJ, Gladwin MT, Steinberg MH. Deconstructing sickle cell disease: reappraisal of the role of hemolysis in the development of clinical subphenotypes. Blood Rev. 2007;21(1):37-47.

52. Hagger D, Wolff S, Owen J, Samson D. Changes in coagulation and fibrinolysis in patients with sickle cell disease compared with healthy black controls. Blood Coagul Fibrinolysis. 1995;6(2):93-9

53. Manci EA, Culberson DE, Yang YM, Gardner TM, Powell R, Haynes J Jr, et al. Causes of death in sickle cell disease: an autopsy study. Br J Haematol. 200;123(2):359-65.

54. Weiner DL, Hibberd PL, Betit P, Cooper AB, Botelho CA, Brugnara C. Preliminary assessment of inhaled nitric oxide for acute vasoocclusive crisis in pediatric patients with sickle cell disease. JAMA. 2003;289(9):1136-42.

55. Morris CR, Kuypers FA, Larkin S, Vichinsky EP, Styles LA. Patterns of arginine and nitric oxide in patients with sickle cell disease with vaso-occlusive crisis and acute chest syndrome. J Pediatr Hematol Oncol. 2000;22(6):515-20.

56. Morris CR, Morris SM Jr, Hagar W, Van Warmerdam J, Claster S, Kepka-Lenhart $\mathrm{D}$, et al. Arginine therapy: a new treatment for pulmonary hypertension in sickle cell disease? Am J Respir Crit Care Med. 2003;168(1):63-9.

57. Paladino SF. Úlcera de membros inferiores na anemia falciforme Rev. Bras. Hematol. Hemoter. 2007;29(3):288-90.

Avaliação: Editor e dois revisores externos

Conflito de interesse: sem conflito de interesse

Recebido: 09/02/2009

Aceito após modificações: 21/09/2009 